\title{
O fluxo imigratório do distrito do Porto para o estado do Pará: borracha, conflitos, epidemias e gênero (1834-1930)*
}

\author{
Cristina Donza Cancela**
}

0 artigo analisa a imigração do distrito do Porto, Portugal, para o estado do Pará, Brasil, entre 1834 e 1930, por meio dos registros de passaporte do Governo Civil do Porto. Observa-se o fluxo ao longo das décadas, ressaltando as questões econômicas e sociais que movimentaram esses deslocamentos, assim como aspectos pontuais, como epidemias e conflitos sociais, com destaque para a Revolta Cabana, em escala local, e a Primeira Guerra Mundial, em nível global. É analisada a influência dos acompanhantes dos titulares dos passaportes e da reemigração no fluxo de migrantes. Também investiga-se o perfil dos imigrantes quanto à origem e naturalidade por distrito e concelho português. Por fim, o artigo problematiza a migração feminina e as questões de gênero que a envolvem, apontando para a assimetria dos deslocamentos de mulheres, sempre em menor quantidade em relação aos homens, mas com crescimento nas primeiras décadas do século XX.

Palavras-chave: Imigração portuguesa. Pará. Fluxo. Perfil. Passaporte. Gênero.

\footnotetext{
* Este artigo é resultado do projeto de pesquisa "Imigração portuguesa: fluxos, características e trajetórias (Pará-Belém/1850-1930)", financiado pelo CNPq. Agradeço aos bolsistas de Iniciação Científica: Paulo Henrique Souza dos Santos, Luana Karina Franca Queiroz e Júlio Ferro Silva da Cunha Nascimento, bem como ao Professor Daniel Souza Barroso pela contribuição.

** Universidade Federal do Pará (UFPA), Belém-PA, Brasil (donza6@gmail.com; https://orcid.org/0000-0002-6075-546X).
} 
Neste artigo analisa-se a presença portuguesa no estado do Pará a partir do fluxo migratório do distrito do Porto, Portugal, entre 1834 e 1930, tendo como principal corpo documental os registros de passaporte. ${ }^{1} \mathrm{~A}$ escolha desse distrito ${ }^{2}$ se deu em razão do intenso contingente de imigrantes portugueses que dele partiu não apenas para o Pará, mas também para outros estados brasileiros (SCOTT, 2000, p. 31). 0 levantamento tem início em 1834 por ser a data do primeiro livro de registro de passaporte conservado no Arquivo Distrital do Porto, terminando em 1930, quando ocorreram mudanças importantes na política administrativa brasileira levadas a efeito no governo Vargas. Entre essas ações, destaca-se a publicação do Decreto n. 19.482, de 12 de dezembro de 1930, que limitou a entrada de estrangeiros em solo brasileiro, particularmente aqueles vindos como passageiros de $3^{\underline{a}}$ classe nos navios, considerados imigrantes. Ressalta-se, ainda, a valorização da mão de obra nacional em detrimento da estrangeira nas empresas. Essas políticas resultaram, entre outras coisas, na busca dos portugueses pela repatriação em função das limitações impostas pelo governo brasileiro (SANTOS, 2017; MENDES, 2010). As mudanças implementadas pelo governo Vargas seguem a linha de outros governos nacionalistas na Europa e nas Américas, que, juntamente com as dificuldades oriundas da Grande Depressão que marcou a década de 1930, provocaram a diminuição do movimento migratório mundial (MASSEY, 2003). Destacam-se, por fim, a crise do comércio da borracha no Pará e a menor liquidez da economia local, desestimulando os deslocamentos para o estado, como será visto adiante.

Embora o período em análise compreenda alguns anos anteriores ao de 1850, a maior parte do levantamento concentra-se na chamada migração portuguesa moderna de massa, iniciada na segunda metade do século XIX, tendo o Brasil como principal destino (PEREIRA, 2002). Entre os motivos desse movimento populacional amplo, destacam-se o crescimento populacional ocorrido em Portugal, a formação de relações capitalistas na agricultura, na pesca e no artesanato com a liberação de mão de obra não absorvida pela indústria incipiente, os limites de terra das famílias e a dificuldade de divisão das propriedades entre os diversos herdeiros e, por fim, os problemas da viticultura e da escassez do algodão, contribuindo para a miséria, o desemprego e/ou subemprego dos trabalhadores portugueses. Paralelamente, verificam-se as facilidades de transporte de trem no interior do país e o aumento da frota de navios a vapor, com viagens mais rápidas e regulares para as diversas partes do Brasil (LEITE, 1991). A estas transformações, agrega-se o apelo das cidades de destino, compondo o mosaico de fatores levantados pela historiografia para entender o maior fluxo de migrantes para o Brasil a partir da segunda metade do século XIX (SERRÃO, 1974; LEITE, 2000; SCOTT, 2000).

\footnotetext{
${ }^{1}$ Os passaportes foram levantados nos livros de registro do Governo Civil do Porto, os quais integram o acervo documental do Arquivo Distrital do Porto.

2 Desde o Decreto de 6 de novembro de 1836, Portugal foi dividido em distritos, concelhos e freguesias. De acordo com Silva (2012, p. 72), “o distrito era dirigido por um administrador-geral, o concelho por um administrador e a freguesia por um regedor. Ao lado destes funcionavam órgãos colegiais: a junta administrativa no distrito, a câmara municipal no concelho e a junta da paróquia na freguesia". Vale ressaltar que os concelhos correspondem ao que seriam os municípios brasileiros.
} 
Vale mencionar que o amplo fluxo imigratório ocorrido no século XIX não é uma singularidade portuguesa e está relacionado ao processo de industrialização da Europa, com a globalização do mercado caracterizada por fluxos maciços de capital, matéria-prima e bens, sendo a migração um processo comum a países como Inglaterra e Espanha, que alcançaram percentuais de saída acima de $20 \%$ em relação ao total da população (MASSEY, 2003, p. 2).

Embora as mudanças econômicas sejam importantes para se compreender a imigração em geral e a portuguesa, em particular, não se pode perder de vista as armadilhas dos estudos clássicos de migração, que partem do pressuposto de que esse processo está pautado na decisão racional de um agente diante de sua condição estrutural/conjuntural e de seu grupo, reforçando uma abordagem baseada na economia e na perspectiva do push-pull (PEIXOTO, 2004). Essa visão é relativizada por análises sociológicas que problematizam a perspectiva do agente racional atomizado, centrado em objetivos econômicos, e evidenciam a importância das relações pessoais, da confiança e das expectativas, associando, dessa forma, racionalidade instrumental e orientação normativa com afetividade, solidariedade, sociabilidade, tradição e redes sociais. Em relação à imigração portuguesa, estudos pontuam a necessidade de se deslocar da construção do imigrante português universal para dar conta da multiplicidade de experiências da migração, memórias e emoções (MATOS, 2008).

É no diálogo das questões econômicas e políticas das sociedades de saída e de destino com as relações sociais e os marcadores sociais da diferença que se deve pensar o imigrante, observando suas práticas limitadas, mas não restringidas, aos processos estruturais. No âmbito desse trabalho, não se tem como discutir as redes sociais estabelecidas pelos imigrantes, embora entenda-se a importância delas no processo de deslocamento. No presente estudo, a ênfase recai na análise quantitativa do fluxo migratório, do sexo e do local de origem dos imigrantes, sem perder de vista as pressões econômicas e políticas que causaram o movimento de população e com atenção às relações sociais e à perspectiva de gênero. Essa perspectiva ajuda a compreender, por exemplo, a invisibilidade da imigração feminina, muitas vezes subsumida nos passaportes coletivos ou nos números, que, embora menores que os masculinos, crescem significativamente ao longo das décadas estudadas (BASSANEZZI, 2012; MATOS; TRUZZI; CONCEIÇÃO, 2018).

Dado o longo período que a abordagem se propõe, realizou-se a análise do fluxo de imigrantes em décadas, acompanhando a linha metodológica de trabalhos sobre a imigração portuguesa, muitos deles utilizando os censos demográficos como fonte (RIBEIRO, 2007; MENEZES; MATOS, 2017). Esse recurso tem a vantagem de dar conta dos quase cem anos levantados, embora limite a discussão mais densa de cada um dos anos em particular, bem como dos processos históricos mais gerais que os recobrem. Ele também dilui eventuais picos e refluxos no deslocamento da população, o que se procurou atenuar com o gráfico da média móvel quinquenal do fluxo, apontando as tendências gerais para além das variações anuais. Da mesma forma, considerando a longa duração e o espaço de um artigo, priorizou-se a discussão de processos históricos que podem ter influenciado mais diretamente a oscilação do fluxo migratório em alguns anos pontuais, como a Cabanagem, as 
epidemias e a Primeira Guerra Mundial. Com isso, espera-se contribuir com a historiografia paraense, que muito discute a presença portuguesa nos séculos XIX e XX, mas que ainda apresenta limites importantes no conhecimento dos números absolutos dessa imigração.

\section{Migração do distrito do Porto ao Pará: os números na historiografia e as fontes}

Pesquisadores portugueses forneceram pistas importantes sobre os números da migração para o Pará quando analisaram o fluxo para o Brasil como um todo, situando a representatividade do estado em relação aos demais. 0 trabalho clássico de Jorge Alves (1994), sobre a migração do Porto para o Brasil, no século XIX, mostra que o Pará concentrou $6 \%$ dos deslocamentos em 1889 . Esse percentual subiu para $17 \%$ em 1899 , o que transformou o estado no segundo destino mais procurado pelos lusos, seguido pelo Amazonas, com 12,9\%. Nessa configuração, o Pará passou à frente de Pernambuco, Bahia e São Paulo/Santos, ficando atrás apenas do Rio de Janeiro (ALVES, 1994, p. 243).

Mais recentemente, Maria José Ferraria e Paulo Amorim (2007), também analisando os registros de passaporte do Porto para o Brasil, entre 1880 e 1890, reiteraram os dados encontrados por Alves, sendo que o Pará despontou como o segundo destino dos imigrantes (FERRARIA; AMORIM, 2007, p. 218). Essa posição se alterou nas primeiras décadas do século XX, como mostra Ricardo Rocha (2011) em seu estudo sobre a imigração do Porto para o Brasil durante a Primeira Guerra Mundial. Nesse período, o Pará passou a ser o terceiro destino mais procurado, ficando atrás do Rio de Janeiro e de São Paulo, mas ainda à frente de estados como Bahia, Pernambuco, Rio Grande do Sul e Amazonas (ROCHA, 2011, p. 270).

Pesquisando os migrantes que saíram de Lisboa com destino ao Pará, Cosme (2015) analisou 1.121 processos de passaportes entre 1886 e 1900. Além do fluxo, o autor investigou o perfil da migração e o que ele chamou de migração pendular, considerando aqueles indivíduos que se deslocaram mais de uma vez ao Pará.

Nos últimos 20 anos, a historiografia paraense também vem investigando os números da imigração lusa para o estado, tendo como fontes preferenciais as habilitações consulares. Os trabalhos não se resumiram à análise quantitativa descritiva desse corpo documental, mas buscaram, por meio dele, chegar mais próximo ao volume de deslocamentos (FONTES, 2002; EMI, 2010; CARVALHO, 2011; CANCELA; COSME, 2016).

As habilitações consulares são livros de registro de imigrantes mantidos pelo Consulado português no Pará entre 1858 e 1959. Embora fundamentais para a compreensão do fluxo migratório, esses registros possuem dois limites importantes. 0 primeiro deles é o fato de os números estarem subestimados, pois o Consulado não possuía estrutura, nem meios, para realizar a fiscalização dos indivíduos que aportavam no Pará, ficando muitos deles invisíveis aos olhos do órgão; havia, ainda, as taxas a serem pagas para a realização dos registros, limitando a regularização do imigrante pobre. Desse modo, entre 1850 e 1918, foram registrados 18.576 imigrantes no Consulado português do Pará, vindos de diversos distritos portugueses. Para esse mesmo período, foram levantados 18.308 passaportes 
emitidos apenas no distrito do Porto, sem considerar outros distritos que também apresentavam intenso movimento de população com destino ao Pará, como Aveiro, Braga e Lisboa. Esses números indicam o sub-registro das habilitações consulares e seu limite para a análise do fluxo migratório.

O segundo limite dessa fonte está associado ao perfil dos inscritos. Boa parte das funções do Consulado estava atrelada à resolução de questões relativas ao patrimônio, ao comércio e aos documentos civis. Esse fato resultou na intensa presença de comerciantes, proprietários e capitalistas nos registros, pessoas com capital que procuravam o órgão para resolver questões de bens e circulação de mercadorias. Em contrapartida, o número de lavradores, pescadores e artesãos era baixo, pois essas pessoas não tinham motivo de ordem econômica para se regularizar, além de terem renda insuficiente para pagar as taxas cobradas pelo Consulado.

Considerando esses dois limites importantes dos registros consulares, iniciou-se a análise do fluxo migratório português utilizando os passaportes como corpo documental. Embora esta fonte também apresente deficiência em relação aos números e ao perfil da imigração - basta lembrar as constantes denúncias de migração clandestina existentes nos jornais e relatórios portugueses -, a emissão de passaportes era feita em meio a uma rede institucional e policial de fiscalização estreita que minimizava os sub-registros. Mesmo considerando a imigração clandestina, o poder de controle e a cadeia administrativa responsável pela emissão dos passaportes eram mais complexos e efetivos do que os alcançados pelo órgão consular. Por isso, o passaporte torna-se uma fonte privilegiada para dar acesso ao conjunto da imigração legal ou mesmo às idas e vindas de Portugal para o Brasil de um único indivíduo, de membros de uma mesma família ou de conterrâneos. Isso é possível pela padronização dos dados nos registros, bem como pela obrigatoriedade e periodicidade ampla dessa fonte, que possibilitam seu tratamento serial, além do fato de que, desde o Decreto de 25 de abril de 1835, a emissão de passaportes foi centralizada nos governos civis existentes em cada distrito português (SOUSA, 2005), que mantém o conjunto desses registros até os dias atuais.

\section{A migração em décadas: a borracha, a Cabanagem e as epidemias}

Portugal, ao longo do século XIX, mais particularmente na segunda metade, iniciou uma política econômica de desenvolvimento das vias de comunicação interna e a implantação de uma indústria que teve no Porto e em Lisboa as duas cidades de maior vitalidade (RODRIGUES, 1995, p. 59). O desenvolvimento urbano e a expressividade política dessas duas cidades litorâneas vão torná-las polos de atração das populações rurais dos concelhos do centro e do interior, em um processo crescente de litoralização da sociedade portuguesa e intensificação da migração interna, pois a saída para o Brasil muitas vezes só ocorria depois de várias etapas de deslocamento dos indivíduos dentro do próprio território português (ALVES, 1994). 
A imigração era estimulada pelas relações comerciais estreitas do Porto com os diversos estados brasileiros, entre eles o Pará. 0 negócio era alimentado pela rede de comerciantes e famílias que transitaram e se estabeleceram nos dois lados do Atlântico, a partir da venda de produtos regionais como o vinho e o azeite. A isso, somava-se a importância, para a economia portuense, das remessas enviadas pelos imigrantes aos familiares que permaneciam em Portugal (ALVES, 1994, p. 59-63).

O Pará tornou-se um território atrativo à imigração desde a primeira metade do século XIX, em grande parte pela atividade extrativista pautada, principalmente, no cacau, mas também na salsaparrilha, na copaíba e no cravo, somada à lavoura e à pecuária. (CHAMBOULEYRON, 2010).

Já a segunda metade do século XIX configurou-se como um período de prosperidade econômica marcada pela economia da borracha, que se estendeu no período de 1850 a 1911, quando entrou em crise devido à queda do preço da goma elástica brasileira no mercado internacional e à concorrência da borracha asiática (SARGES, 2002). Nesse período, Belém passou por um processo de urbanização crescente, estimulado pelo aumento da renda pública e pela abertura da navegação do rio Amazonas aos navios estrangeiros. Com o fim do tráfico de escravos africanos, houve a busca por mão de obra alternativa, o que, juntamente com a propaganda oficial de atração de população, fez com que a capital recebesse um importante contingente migratório nacional e internacional, com destaque, neste último caso, para os portugueses (FONTES, 2002).

Em números, o levantamento dos registros de passaporte do distrito do Porto ao Pará, entre 1834 e 1930 , alcançou o total de 18.308 imigrantes.

GRÁFICO 1

Número de passaportes anual e média móvel quinquenal do distrito do Porto ao Pará

1834-1930

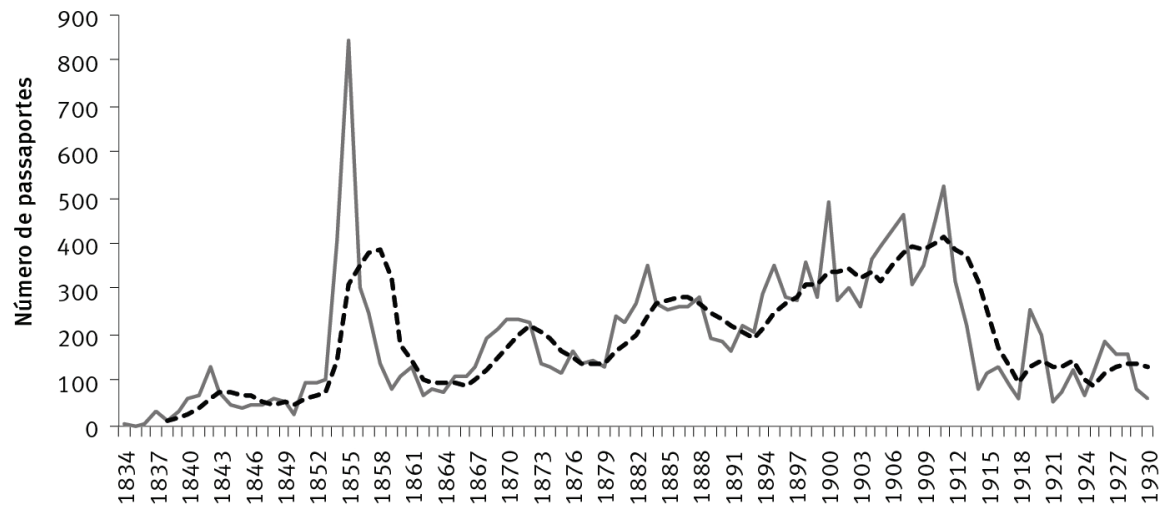

Anos

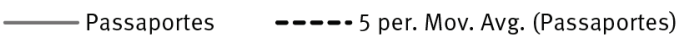

Fonte: Livro de registro de passaportes do Governo Civil do Porto. Acervo do Arquivo Distrital do Porto. 
A linha da média móvel quinquenal exibida no Gráfico 1 demonstra que a imigração se intensificou a partir de meados da década de 1850, mantendo tendência ascendente ao longo das décadas de expansão da economia gomífera (1850-1911) e diminuindo significativamente nos anos de crise do comércio da borracha. É interessante observar que o ano de 1911 é considerado pela historiografia o marco do declínio econômico que vai assolar o estado. Ao analisar o gráfico, observa-se que é justamente a partir desse ano que ocorre a queda do fluxo migratório portuense.

Por sua vez, os números da primeira metade do século XIX demonstram que foram poucos os que chegaram ao estado naquele período, em um total de 751 indivíduos. Isso corresponde a 4,1\% dos deslocamentos entre 1834 e 1930.

Para entender esse quadro pouco expressivo de deslocamentos ao Pará na primeira metade do século XIX, convém lembrar que era um período adverso para os portugueses que viviam no estado em razão de importantes conflitos políticos de caráter antilusitano, como a revolta social dos cabanos ocorrida de 1835 a $1840 .{ }^{3}$ Esse conflito pode ter inibido um movimento de população mais acentuado, embora não o tenha interrompido, uma vez que foram emitidos 145 passaportes naquele período.

É bem verdade que nenhum deles foi registrado em 1835, ano em que os cabanos tomaram o poder político da capital paraense e, na sequência, promoveram a chacina de seus inimigos, entre eles portugueses e maçons (RICCl, 2007). Contudo, nos anos posteriores, a emissão de passaportes voltou a ser registrada. Em 1836, foram solicitados seis passaportes, quantidade que aumentou para 32 em 1837, diminuiu para dez em 1838, voltou a subir para 34 em 1839 e chegou a quase o dobro desse contingente no ano final do conflito, em 1840, quando 63 passaportes foram emitidos. Com esses números, observa-se que a Cabanagem, embora tenha limitado os deslocamentos, não interrompeu a mobilidade de portugueses do Porto ao Pará.

Com o fim do conflito, os fluxos voltaram a crescer, alcançando um total de 127 passaportes emitidos apenas em 1842, contra os 145 registrados nos cinco anos de duração do movimento cabano. A partir de 1842, os números diminuíram e se mantiveram na casa dos 50 a 75 registros até 1850 .

Pode-se pensar que esse pico em 1842 está relacionado a um contingente retido de imigrantes que não se aventuraram a realizar a viagem nos anos da revolta cabana, mas também pode estar associado ao cabralismo e às questões políticas e econômicas que

\footnotetext{
3 A Cabanagem foi um movimento que eclodiu em Belém do Pará em 1835, seguindo até 1840. Alcançou não apenas a capital do estado, mas também cidades do interior e do litoral norte e nordeste, deixando mais de 30 mil mortos nos anos de conflito. 0 movimento foi protagonizado por mestiços, índios e africanos pobres ou escravos. Apregoava o ódio ao mandonismo branco e português, lutando por direitos e liberdade (RICCI, 2007).
} 
envolveram Portugal e resultaram na revolta conhecida como "Maria das Fontes", 4 pois esse mesmo pico foi verificado por Jorge Alves para o Rio de Janeiro (ALVES, 1994).

Desse modo, conclui-se que o fluxo migratório do Porto ao Pará, embora tenha se reduzido no período da revolta social dos cabanos, não sendo registrada nenhuma emissão no ano inicial do conflito, não foi interrompido, chegando mesmo a ultrapassar a casa dos 50 deslocamentos em 1840, um número não muito distante do encontrado para os demais anos daquela primeira metade da centúria.

Ainda que menores aos da segunda metade do século XIX, esses números são bastante significativos na medida em que evidenciam a presença constante de portugueses no Pará, com negócios voltados aos produtos extrativistas e ao comércio de vinho e de azeite, bem como com laços alimentados pelas redes sociais construídas por várias gerações de famílias deslocadas (CANCELA, 2016). Ao analisar os pedidos de permissão de viagem feitos aos administradores de Portugal no período joanino (1808-1821), Vieira Junior e Barroso (2010, p. 209) levantaram uma média de 17 passaportes por ano sendo expedidos ao Pará, “mesmo em época joanina, com as incertezas rondando um Portugal em meio a avanços e recuos de invasões estrangeiras e um regente afastado".

A partir do levantamento dos passaportes de vários Arquivos Distritais Portugueses e do Arquivo Histórico Ultramarino, Guimarães (2018) chegou ao contingente de cerca de 1.400 pedidos de passaporte ao Pará entre 1800 e 1850. Portanto, quase o dobro dos 751 encontrados no levantamento do Distrito do Porto. Como afirmado anteriormente, menos do que o número absoluto, chama a atenção a presença constante de portugueses chegando e se estabelecendo no estado nesse período. Esta é uma realidade não apenas no Pará, mas também em outras localidades brasileiras, como lembra Gladys Ribeiro (2007) ao tratar da presença portuguesa no Rio de Janeiro, ressaltando que, no Primeiro Reinado e nas Regências, “os trabalhadores portugueses constituíam percentagem significativa da população total trabalhadora livre da Corte”.

Esse quadro tímido, porém, constante, de mobilidade ganhou força na segunda metade do século XIX. O Pará, assim como as demais localidades brasileiras, recebeu um contingente bem mais expressivo de imigrantes portugueses. Como destaca Marie-Jo Ferreira (2013), "no fim do século XIX, a emigração portuguesa torna-se uma emigração mais maciça, muito mais pobre, sem rede de acolhimento no Brasil”. Alavancada pelo crescimento demográfico e pela crise financeira portuguesa já destacada, essa onda migratória tinha o Brasil como principal destino. Outros fatores também estão associados ao aumento nos deslocamentos, como a melhoria dos transportes e o investimento na navegação a vapor por empresas estrangeiras, diminuindo o tempo de viagem, embora aumentassem o custo

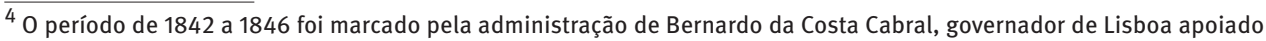
pela rainha, que restabeleceu a conservadora carta constitucional de 1826. Ele ficou conhecido pela perseguição aos adversários políticos, pela violação à praxis eleitoral e pelo favoritismo declarado aos seus aliados comerciais. Em 1846, eclodiu a Revolução Portuguesa contra os limites impostos por Cabral aos direitos tradicionais à terra, que teve as províncias do Norte como força e as mulheres agricultoras como protagonistas importantes, motivo pelo qual o movimento ficou conhecido como “Maria da Fonte” (HOMEM, 2000).
} 
das passagens. Segundo Joaquim Leite (1991, p. 751), "era preciso dinheiro ou crédito para pagar uma passagem que, sendo mais rápida, mais confortável e segura, era também significativamente mais cara". Embora onerosos, os vapores eram mais confortáveis e realizavam viagens em menor tempo, previsíveis e seguras, fragilizando os navios à vela. As empresas de transporte mantinham correspondentes e agentes que viabilizavam os documentos necessários à migração, driblando as dificuldades burocráticas na emissão de passaportes e passagens. Entre essas empresas, destaca-se a Agência Abreu, fundada em 1840, cujo proprietário serviu de agente a um número expressivo de passaportes emitidos no Porto com destino ao Pará, na segunda metade do século XIX (SOUSA, 2009). ${ }^{5}$

Para termos ideia desse aumento, apenas entre 1851 e 1860, os deslocamentos alcançaram o patamar de 2.421 imigrantes, contra os 751 levantados para o período de 1834 a 1850. 0 aumento foi, de certa forma, esperado, tendo em vista a já referida migração moderna de massa e a ascensão do valor da goma elástica no mercado internacional, sendo o Pará um de seus principais fornecedores. Para além desses fatores estruturais que impulsionam a mobilidade, há processos pontuais que fazem o fluxo oscilar de forma acentuada, como o verificado em 1855 e 1856, quando eclodiu a epidemia do cólera no Porto (ALMEIDA, 2014). Dos 2.421 passaportes da década, 842 foram emitidos apenas em 1855, ano de início da epidemia. Isso significa que 35\% dos deslocamentos daquela década ocorreram em um único ano. É curioso observar que, nesse mesmo ano, Belém também vivia, em suas ruas, as consequências da epidemia do cólera, que aportou na cidade em maio de 1855 , vinda do Porto, chegando a matar 1.050 pessoas na capital paraense (BELTRÃO, 2004, p. 123). No distrito do Porto, Jorge Alves afirma que a epidemia foi detectada no dia 15 de maio, em Gaia, concelho limítrofe ao do Porto, chegando a atingir 4.760 pessoas, das quais 1.973 teriam falecido (ALVES, 1994, p. 169). Portanto, se a princípio esse aumento espetacular no fluxo de 1855 pode ser entendido em função da epidemia do cólera no Porto, como entender o deslocamento para Belém, uma cidade também mergulhada nas agruras da mesma doença carregada nos vapores portugueses? A despeito da ascensão contínua do comércio da borracha no Pará, o fluxo de imigrantes portuenses não foi tão expressivo na década posterior, chegando, entre 1861 e 1870, a 1.334 passaportes emitidos, um pouco mais da metade do número encontrado para o decênio anterior. Isso reforça ainda mais a importância da epidemia do cólera nos números levantados para aquele período. Excluindo os anos de 1855 e 1856, nos quais os efeitos da epidemia se fizeram presentes, observa-se que a média da década de 1851 a 1860 seria de 146 passaportes emitidos por ano, contra 133 de 1861 a 1870. Uma queda, portanto, não tão acentuada. 0 que ocorre é que os anos de 1855 e 1856 foram atípicos, com um pico ascendente, provavelmente potencializado pelos efeitos da epidemia do cólera.

Entre 1871 e 1880 houve uma alta discreta, chegando a 1.653 passaportes expedidos. Foi a partir da década seguinte que esses registros aumentaram significativamente, voltando para

\footnotetext{
${ }^{5}$ A Agência Abreu era administrada por Daniel Luiz Vieira d’Abreu, filho do fundador, Bernardo Luís Vieira de Abreu. É considerada a agência mais antiga ainda em funcionamento em Portugal, tendo sido fundada no Porto em 1840 (SOUSA, 2009).
} 
a casa das duas mil migrações, mais especificamente, 2.555, entre 1881 e 1890, e 2.925, de 1891 a 1900. É importante destacar, em relação a esse último período, que só em 1900 chegaram 492 imigrantes, um número que corresponde a 19\% do deslocamento total da década e pode ser compreendido em consequência do cerco sanitário sofrido pela cidade do Porto, por conta da epidemia de peste bubônica iniciada no segundo semestre de 1899 (PONTES, 2012). Mais uma vez, uma epidemia alterou substancialmente o fluxo de pessoas ao Pará. Isso fica mais evidente quando se observa que, em 1900, chegaram 492 imigrantes. Em 1899 esse número foi de apenas 284 e, em 1901, de 273 indivíduos. Ou seja, o cerco sanitário ocorreu no segundo semestre de 1899 e seu reflexo fez a migração de 1900 chegar ao patamar de quase 500 passaportes emitidos, sendo que nos anos anteriores e posteriores essas emissões não alcançavam nem mesmo a casa dos 300 passaportes.

Na sequência dos anos de 1901 a 1910, o aumento se manteve, sendo registrados 3.593 passaportes, o maior patamar encontrado para o período analisado.

Embora diversos autores tenham apontado a importância da economia da borracha para o aumento da imigração estrangeira no Pará, o levantamento dos passaportes do Porto traduziu em números essa hipótese, mostrando a relação estreita entre a ascensão do valor e do comércio internacional da goma elástica e os deslocamentos migratórios portugueses a partir do Porto.

A proximidade dessa relação ocorre de tal forma que, com a crise da economia gomífera que se manifestou a partir de 1911, houve uma diminuição brusca do processo migratório, chegando a 1.993 indivíduos entre 1911 e 1920, o que corresponde a pouco mais da metade do número de pessoas que saíram do Porto em direção ao Pará no decênio anterior.

Além das questões relativas ao declínio do comércio da borracha, há também que se considerar, nesse período, os impactos da Primeira Guerra Mundial nas migrações transatlânticas. Como alerta Ricardo Rocha (2011, p. 256), analisando a migração do Porto para o Brasil como um todo, esse período "é caracterizado por um acentuado decréscimo do fluxo de emigrantes àquele destino". 0 Pará não fugiu a essa tendência e o fluxo de imigrantes durante o período do conflito (1914-1918) teve uma média de entrada de 96 indivíduos por ano. Esse número está bem abaixo dos anos anteriores (1912 e 1913), nos quais a média de entrada foi de 269 imigrantes por ano, a despeito da crise da borracha a partir de 1911.

O número expressivo de deslocamentos nos anos que antecederam a Primeira Guerra Mundial não foi exclusivo do Pará, sendo também verificado para os demais estados. Segundo Rocha (2011, p 256), “os três anos imediatamente precedentes ao início do conflito (1911-1913) foram precisamente aqueles em que se registraram os maiores volumes da história da emigração portuguesa para o Brasil”. De qualquer forma, mesmo o patamar expressivo de deslocamentos anteriores aos anos de guerra não foi suficiente para equiparar os números desse período com os do anterior.

Entre 1921 e 1930, último decênio do levantamento, chegou-se ao total de 1.083 passaportes, mantendo a tendência de queda agravada pela crise capitalista de 1929, que fez com que a imigração diminuísse. Para se ter dimensão dessa queda, migraram 
apenas 82 pessoas, em 1929, e 60, em 1930, números que correspondem aos moderados deslocamentos verificados ainda na primeira metade do século XIX.

Assim, se a crise no comércio da borracha contribuiu para o declínio da imigração portuense ao Pará, o conflito bélico e a depressão econômica de 1929 foram eventos de escala global que também diminuíram as saídas não apenas para o estado, mas para todo o Brasil.

No Pará, a instabilidade econômica se traduziu nas diversas casas comerciais que abriram falência, nos imóveis, navios e seringais levados a leilão, nas dificuldades para a venda de bens na praça local por falta de comprador e na solicitação de empréstimo por parte da administração estatal, que alegou a quebra da economia (CANCELA, 2011).

Essas notícias chegavam às paragens portuguesas, possivelmente, por meio das cartas que circulavam entre parentes e amigos, mas, certamente, despontavam nas folhas dos principais periódicos. Por exemplo, o jornal O Commercio do Porto, importante folha da cidade do Porto, em sua coluna intitulada "Cartas do Pará", mensalmente publicada, noticiou diversas reportagens sobre a instabilidade da praça paraense em função da queda do preço da borracha. A derrocada do Banco do Pará e as assembleias para evitar o seu fechamento eram noticiadas com detalhes dos balancetes da instituição financeira e do andamento das reuniões, de acordo com os credores. ${ }^{6}$ Da mesma forma, referências às casas comerciais e aos seringais falidos figuravam nas páginas do jornal português. ${ }^{7}$ A publicação de matérias sobre a economia paraense interessava não apenas àqueles que mantinham negócios no estado, mas também a parentes que enviavam remessas de dinheiro e a possíveis migrantes que pretendiam sair em busca de trabalho e renda, presumidamente desestimulando os deslocamentos.

\section{Deslocamento, reemigração e acompanhantes: redimensionando o fluxo}

Os números dos fluxos apresentados anteriormente podem variar não apenas em função da imigração clandestina, mas também por pelo menos dois outros pontos importantes a serem destacados: a presença de acompanhantes junto aos titulares dos passaportes e 0 processo de reemigração.

Analisando inicialmente o primeiro aspecto, observa-se que os passaportes eram individuais, contudo, em muitos deles, há registro de pessoas acompanhando o titular até pelo menos 1919, quando o Decreto n. 5.624, de 10 de maio de 1919, proibiu a emissão de passaportes coletivos (FERREIRA, 2007, p. 146). Do total de 18.308 passaportes levantados, foi arrolada a presença de acompanhantes em $8 \%$ deles, um percentual relativamente baixo quando comparado aos números observados por Carmem Sarmento (2009, p. 295) em sua análise sobre a imigração de Braga para o Brasil, em que a autora encontrou 17,6\% de passaportes coletivos. Convém lembrar que Braga, juntamente com Porto e Aveiro, estava entre os principais distritos de origem dos portugueses que imigraram para o Pará e Brasil como um todo.

\footnotetext{
$\overline{6}$ Jornal 0 Commercio do Porto, de 7 de janeiro de 1901.

7 Jornal $O$ Commercio do Porto, de 31 de maio de 1901.
} 
Entre os indivíduos que tinham passaporte coletivo, $68 \%$ eram do sexo masculino e $32 \%$ do feminino, portanto, havia uma acentuada presença de homens viajando, principalmente, com seus filhos e esposas. Essa diferença tão acentuada é, igualmente, singular em relação aos dados levantados por Carmem Sarmento (2009, p. 299) para Braga, cuja relação de passaportes coletivos se mostrou equilibrada, sendo $51 \%$ pertencentes a homens e $49 \%$ a mulheres, a despeito da migração daquele distrito ser predominantemente masculina, tal como a do distrito do Porto.

Por vezes, os acompanhantes vinham referidos com nome e relação de parentesco, afinidade ou trabalho em relação ao titular do documento; outras vezes, no entanto, há apenas a referência de sua existência, sem quantificá-los ou nomeá-los. Por exemplo, foram encontradas nos registros frases como "seus filhos o acompanham", não tendo como saber a quantidade de filhos ou mesmo o sexo ou a idade deles. Considerando os acompanhantes e não apenas os titulares dos passaportes, o número de imigrantes anteriormente apresentado se amplia.

Nos documentos em que foi possível obter informação mais detalhada dos acompanhantes, o que significou identificar a quantidade, o sexo e, com um pouco mais de sorte, a relação com o titular do passaporte, chamou a atenção a intensa presença feminina, em um total de 1.205 mulheres, número bem superior aos 872 homens identificados. Embora alguns documentos não especificassem a relação do acompanhante com o titular, naqueles em que essa informação constava verificou-se que a maior parte das mulheres era formada por esposas (544) e filhas (552). Na sequência, havia irmãs (20), criadas (9), enteadas (5), sobrinhas (3), netas (3), cunhadas (3) e tia (1). ${ }^{8}$

Em relação aos homens, nenhum esposo foi registrado como acompanhante, o que era esperado tendo em vista a legislação, como a de 1863, marcada por uma forte assimetria de gênero, em que a autorização do marido se fazia necessária para que a mulher viajasse (LEITE, 1987, p. 476). Já o número de filhos foi bastante expressivo, sendo o segmento mais encontrado, atingindo um total de 787 indivíduos. Na sequência, aparecem os irmãos (53), sobrinhos (9), netos (4), enteados (3) e criados (2).

$\mathrm{Na}$ contramão dos acompanhantes, que aumentam o contingente de imigrantes portuenses para o Pará, foram identificados indivíduos que realizaram o deslocamento mais de uma vez, aparecendo de forma duplicada na listagem ao renovarem seus passaportes. Se considerarmos os imigrantes que realizaram apenas uma viagem, do total de 18.308, chega-se a 15.901, ou seja, 1.568 pessoas solicitaram passaporte duas ou mais vezes, o que corresponde a $8,5 \%$ dos documentos expedidos. Esse percentual está próximo aos $6,5 \%$ encontrados por Alves (1994, p. 257), mas ficou abaixo daquele observado por João Cosme (2015) para Lisboa, em que, dos 1.121 passaportes solicitados, 130 correspondiam à segunda solicitação, ou seja, 11,6\%.

\footnotetext{
${ }^{8} 0$ número de mulheres com parentesco, afinidade e/ou relação de trabalho aqui apresentado não coincide com o total anteriormente indicado (1.205), pois, por vezes, o passaporte especificava o nome de uma mulher sem indicar a relação com o titular. 0 mesmo vale para os dados relativos aos homens, que serão discutidos mais à frente.
} 
Não é possível saber os motivos que levavam os indivíduos a realizarem duas ou mais viagens do Porto ao Pará, contudo, algumas hipóteses podem ser levantadas: nova necessidade de trabalho e renda após o retorno e um período de estadia em terras portuguesas; existência de bens, negócios e/ou trabalho nas duas localidades; permanência da família no Porto, a despeito de alguns parentes viverem no Pará; e eventos relacionados ao lazer, às questões de saúde, celebrações familiares ou falecimentos.

Não se pode perder de vista também que, com a proliferação dos vapores e a diminuição do tempo da viagem, houve maior facilidade em realizar a travessia, pelo menos para aqueles que amealhavam algum recurso.

0 conjunto desses fatores potencializou a reemigração portuguesa, tornando-a uma prática comum para todo o Brasil, pois, como destaca Ilana Rocha (2007, p. 26) em seu trabalho sobre a reemigração em São Paulo, ela não figurava como uma característica local, mas sim como um movimento que esteve presente entre os imigrantes de diversos estados brasileiros, sendo uma tendência do movimento europeu para a América.

Em boa parte dos passaportes destes reemigrados, não existia o registro da atividade exercida pelo seu portador, havendo apenas o termo "trabalhador" para definir a ocupação, uma expressão genérica que não permite saber o ofício específico do indivíduo. Entre aqueles que tiveram a atividade detalhada, os comerciantes se destacaram, seguidos pelos carpinteiros, empregados no comércio, marítimos, ourives, tanoeiros, pedreiros e proprietários, este último grupo sem esclarecer que tipo de propriedade se estava tratando. Na sequência, em menor proporção, aparecem alfaiates, trolhas, padeiros, mineiros e pessoas ligadas à lavoura. Entre as mulheres, das poucas que possuíam o registro de atividade, predominavam as domésticas e criadas.

Por vezes, esses indivíduos realizaram mais de duas viagens ao longo dos anos, como é o caso do negociante de Santo Tirso, Albano Alfredo da Costa Mesquita, que veio ao Pará pela primeira vez em 1894, com a idade de 16 anos. ${ }^{9} \mathrm{Em} 1902$, portanto, oito anos depois, retornou ao estado, já com 24 anos, ${ }^{10}$ voltando em 1904 e 1906, sempre na condição de negociante e solteiro. ${ }^{11}$

Comerciantes como Albano estavam entre aqueles que mais renovaram seus passaportes. No entanto, a esses indivíduos juntavam-se os que viviam de seus ofícios, tais como o ourives do concelho de Gondomar, Alberto Martins de Sousa, que chegou ao Pará em 1898, com 19 anos de idade, também na condição de solteiro, ${ }^{12}$ e por mais três vezes voltou a solicitar passaporte, em 1906, 1909 e $1915 .^{13}$

\footnotetext{
${ }^{9}$ Registro de passaporte, Governo Civil do Porto, n. 1093, livro 03, p. 183. Acervo do Arquivo Distrital do Porto.

${ }^{10}$ Registro de passaporte, Governo Civil do Porto, n. 612, livro 124, p. 102 v. Acervo do Arquivo Distrital do Porto.

${ }^{11}$ Registro de passaporte, Governo Civil do Porto, n. 387, livro 128, p. 65. Registro de passaporte, Governo Civil do Porto, n. 519, livro 133, p. 87. Acervo do Arquivo Distrital do Porto.

${ }^{12}$ Registro de passaporte, Governo Civil do Porto, n. 505, livro 118, p. 85. Acervo do Arquivo Distrital do Porto.

${ }^{13}$ Registro de passaporte, Governo Civil do Porto, n. 567, livro 132, p. 95. Registro de passaporte, Governo Civil do Porto, n. 551, livro 147, p. 92 v. Registro de passaporte, Governo Civil do Porto, n. 789, livro 170, p. 133v. Acervo do Arquivo Distrital do Porto.
} 
Entre as mulheres, destaca-se a modista Delfina Maria Tavares Martins, moradora na rua Padre Prudêncio, localizada no comércio de Belém. Embora o primeiro passaporte dela date de $1915,{ }^{14}$ Delfina teria aportado no estado, pela primeira vez, em 1912, segundo dados do seu registro consular de $1916 .{ }^{15} \mathrm{Em}$ seu passaporte, Delfina declarou a condição de solteira, embora viesse acompanhada do filho de um ano de idade. Em 1919, um segundo passaporte foi emitido em seu nome e um segundo filho, de apenas seis meses, foi registrado. Contudo, desta feita, a condição de casada foi declarada. ${ }^{16} \mathrm{Em} \mathrm{1927,} \mathrm{ela}$ retornou ao Pará, já com 31 anos de idade, mas nenhum filho foi registrado como seu acompanhante. Nascida no concelho do Porto, freguesia de Santo Idelfonso, sabia ler e escrever, tendo assinado seu nome e declarado apenas o nome de seu pai, José Antônio da Silva, e de sua mãe, Augusta Tavares da Silva, no registro. Em momento algum o nome do cônjuge é citado na documentação, seja dos passaportes, seja em sua habilitação no Consulado, datada de 1916, em que aparece como solteira, embora em 1915 seu passaporte indicasse a presença de um filho.

Por meio desses sujeitos é possível ter acesso aos diferentes perfis daqueles que realizaram a viagem do distrito do Porto ao Pará por mais de uma vez. Como referido, é difícil saber os motivos das viagens, o tempo que ficaram no estado, se retornaram ao Porto ou permaneceram no Brasil. Os limites da fonte pontuam o fim dos rastros - e, "se para uns o Brasil foi um destino sem retorno, outros houve que cruzaram várias vezes o Atlântico, cuidando dos seus interesses nos dois lados do Oceano" (MAIA; MONTEIRO, 2015, p. 126).

A despeito de suas limitações, os dados relativos à reemigração, bem como aos acompanhantes, permitem redimensionar o fluxo migratório, evidenciando suas nuances e especificidades. Se o número de acompanhantes amplia o volume da mobilidade, a reemigração o retrai. Por sua vez, se a reemigração foi marcadamente realizada por homens, muitos deles ligados ao comércio e, em menor proporção, aos ofícios, entre os acompanhantes, destacaram-se as mulheres.

\section{Perfil dos imigrantes quanto ao sexo}

A imigração portuguesa para o Brasil foi predominantemente masculina, havendo uma elevação do número de mulheres no final do século XIX para o início do XX. Este perfil não foi diferente do encontrado para o Pará.

\footnotetext{
${ }^{14}$ Registro de passaporte, Governo Civil do Porto, n. 656, livro 170, p. 110. Acervo do Arquivo Distrital do Porto.

${ }^{15}$ Livro de registro de habilitação do Consulado português no Pará. Habilitação n. 1840, de 7 de junho de 1916. Imagem p1040209. Acervo do Grêmio Literário Português.

${ }^{16}$ Registro de passaporte, Governo Civil do Porto, n. 572, livro 179, p. 86v. Registro de passaporte, Governo Civil do Porto, n. 514, livro 224, p. 82v. Acervo do Arquivo Distrital do Porto.
} 
TABELA 1

Razão de sexo dos imigrantes do distrito do Porto com destino ao Pará - 1834-1930

\begin{tabular}{|c|c|c|c|c|c|c|}
\hline \multirow[t]{2}{*}{ Períodos } & \multicolumn{2}{|c|}{ Homens } & \multicolumn{2}{|c|}{ Mulheres } & \multirow[t]{2}{*}{ Total } & \multirow{2}{*}{$\begin{array}{l}\text { Razão de } \\
\text { Sexo }\end{array}$} \\
\hline & $\mathrm{N}$ & $\%$ & $\mathrm{~N}$ & $\%$ & & \\
\hline $1834-1840$ & 146 & 0,9 & 3 & 0,2 & 149 & 48,67 \\
\hline $1841-1850$ & 596 & 3,6 & 6 & 0,3 & 602 & 99,33 \\
\hline $1851-1860$ & 2.386 & 14,5 & 35 & 1,9 & 2.421 & 68,17 \\
\hline $1861-1870$ & 1.283 & 7,8 & 51 & 2,8 & 1.334 & 25,16 \\
\hline $1871-1880$ & 1.576 & 9,6 & 77 & 4,2 & 1.653 & 20,47 \\
\hline $1881-1890$ & 2.414 & 14,6 & 141 & 7,7 & 2.555 & 17,12 \\
\hline 1891-1900 & 2.643 & 16,0 & 282 & 15,5 & 2.925 & 9,37 \\
\hline 1901-1910 & 3.245 & 19,7 & 348 & 19,1 & 3.593 & 9,32 \\
\hline 1911-1920 & 1.458 & 8,8 & 535 & 29,4 & 1.993 & 2,73 \\
\hline 1921-1930 & 740 & 4,5 & 343 & 18,8 & 1.083 & 2,16 \\
\hline Total & 16.487 & 100,0 & 1.821 & 100,0 & 18.308 & 9,05 \\
\hline
\end{tabular}

Fonte: Livro de registro de passaporte do Governo Civil do Porto. Acervo do Arquivo Distrital do Porto.

Em todas as décadas, o cálculo da razão de sexo evidencia a acentuada presença masculina no período estudado. Dessa forma, se ainda na primeira metade do século XIX foi registrada a chegada de 48 homens para cada mulher, esse número cresceu nas décadas seguintes, quando eram 99 homens para cada mulher (1841-1850), para logo diminuir sucessivamente nos anos posteriores, chegando a nove homens para cada mulher na virada do século XIX para o XX, período de ascensão significativa da economia gomífera e do fluxo migratório. Já nos anos de crise econômica, houve a presença de dois homens para cada mulher, diminuindo significativamente a diferença quantitativa de deslocamentos entre os sexos. 0 aumento da migração feminina nos anos iniciais da República foi observado também para outros estados brasileiros. Em estudo realizado sobre a imigração portuguesa para o Rio de Janeiro, Lená Menezes e Maria Izilda Matos (2017, p. 18) observaram "um notável crescimento na presença da mulher no conjunto da colônia portuguesa". Em São Paulo, Maria Izilda Matos (2013, p. 76) destaca que a emigração portuguesa foi prioritariamente masculina, "mas o contingente feminino cresceu gradativamente".

No distrito do Porto, Ricardo Rocha (2011, p. 262) pontua que, nos anos da Primeira Guerra Mundial, houve o aumento da presença feminina, que chegou a duplicar o seu peso no fluxo migratório. 0 autor atribui esse fato à emancipação feminina, em parte, impulsionada pela guerra, com a imersão das mulheres em posições econômicas e sociais mais vantajosas, além do reagrupamento das famílias em solo brasileiro, diante da desesperança de residir em território português, muito próximo ao conflito bélico e à crise que se instalaria no pós-guerra.

À vista disso, a média dos quase cem anos de levantamento dos passaportes portuenses é de nove homens para cada mulher, um deslocamento expressivo, mas ainda assim menor, que deve ser compreendido em uma perspectiva de gênero para se dimensionar as dificuldades de uma mulher solteira, sozinha ou com filho, em lidar com as representações negativas de viajar sem acompanhante masculino para um local desconhecido. A assimetria 
na representação da imigração de homens e de mulheres se atualizava em práticas como as mencionadas por Caroline Brettell (1991), ao realçar que pesava negativamente para a família a migração de uma filha, pois era sinal de pobreza dos pais ter que chegar a tal expediente. Isso fazia com que as famílias com um pouco mais de recurso evitassem a migração das mulheres, privilegiando apenas a dos varões.

Da mesma forma, analisando a imigração portuguesa para São Paulo, Maria Izilda Matos, Osvaldo Truzzi e Carla Conceição (2018) observam que “as experiências migratórias femininas têm sido pouco analisadas, permanecendo a tendência à observação dos fluxos sob a perspectiva universal masculina". Esta invisibilidade, segundo os autores, precisa ser relativizada, pois a entrada feminina, embora ocorresse em menor percentual, apresentou tendência de aumento crescente ao longo dos anos, o que também se verificou nos dados encontrados no caso do Pará, ainda mais se forem agregados a essas entradas os acompanhantes nos passaportes coletivos, muitos deles mulheres invisibilizadas pela legislação.

\section{Perfil dos imigrantes quanto à origem}

Quando se verifica a origem dos imigrantes que tiraram seus passaportes no Porto com destino ao Pará, observa-se que 6.709 deles pertenciam a outros distritos portugueses, continentais ou insulares, o que correspondeu a $36,6 \%$ dos passaportes.

Essa presença expressiva de pessoas de outros distritos que não o do Porto é interessante, afinal, desde 1835 , os passaportes deveriam ser emitidos no distrito de origem daqueles que migravam. Desse modo, apenas os naturais podiam solicitar passaporte no Porto ou os que lá residissem há pelo menos seis meses (ALVES, 1993, p. 89). A presença de pessoas de distritos como Aveiro, Braga, Guarda, Viana do Castelo, Viseu e Vila Real, para ficar naqueles que apresentaram maior fluxo, evidencia a já destacada existência de mobilidade interna em Portugal e a força do Porto como polo urbano de atração. Os distritos limítrofes ao do Porto, como Braga, Aveiro e Viseu, foram, justamente, os que apresentaram o maior percentual de indivíduos que solicitaram passaporte junto ao Governo Civil do Porto.

Recortando ainda mais o estudo, há registros dos 18 concelhos que compunham o distrito do Porto e que apresentaram uma amostragem heterogênea no processo de mobilidade para terras paraenses.

Na Figura 1 observa-se que o concelho de Vila Nova de Gaia foi o local de origem da maior parte dos imigrantes que se transferiram para o estado do Pará, correspondendo a $24,2 \%$ do total. Isso significa que, dos 11.599 imigrantes do distrito do Porto, entre homens e mulheres, 2.789 eram naturais de seu concelho limítrofe, Gaia. Na sequência, aparecem os concelhos do Porto (17\%), Gondomar (12,3\%) e Bouças (12,4\%), atualmente denominado Matosinhos. Por conseguinte, os concelhos mais próximos à cidade do Porto foram, justamente, os que apresentaram maior percentual imigratório, chegando a números superiores a 1.000 deslocamentos em Gondomar e Bouças/Matosinhos e acima de 2.000 em Vila Nova de Gaia. 
TABELA 2

Imigrantes do Porto com destino ao Pará, por sexo, segundo distritos de origem 1834-1930

\begin{tabular}{|c|c|c|c|c|}
\hline \multirow{2}{*}{ Distritos } & \multirow{2}{*}{ Homem } & \multirow{2}{*}{ Mulher } & \multicolumn{2}{|c|}{ Total } \\
\hline & & & $\mathrm{N}$ & $\%$ \\
\hline Angra do Heroísmo & 2 & 1 & 3 & 0,0 \\
\hline Aveiro & 1.464 & 100 & 1.564 & 8,5 \\
\hline Beja & 4 & 1 & 5 & 0,0 \\
\hline Braga & 1.008 & 85 & 1.093 & 5,9 \\
\hline Bragança & 68 & 25 & 93 & 0,5 \\
\hline Castelo Branco & 12 & 3 & 15 & 0,0 \\
\hline Coimbra & 52 & 5 & 57 & 0,3 \\
\hline Faro & 4 & 1 & 5 & 0,0 \\
\hline Funchal & 7 & 3 & 10 & 0,0 \\
\hline Guarda & 200 & 40 & 240 & 1,3 \\
\hline Leiria & 24 & 0 & 24 & 0,1 \\
\hline Lisboa & 40 & 10 & 50 & 0,2 \\
\hline Ponta Delgada & 3 & 0 & 3 & 0,0 \\
\hline Portalegre & 8 & 0 & 8 & 0,0 \\
\hline Porto & 10.698 & 901 & 11.599 & 63,3 \\
\hline Santarém & 13 & 3 & 16 & 0,0 \\
\hline Setúbal & 3 & 1 & 4 & 0,0 \\
\hline Viana do Castelo & 424 & 39 & 463 & 2,5 \\
\hline Vila Real & 452 & 96 & 548 & 2,9 \\
\hline Viseu & 1.437 & 288 & 1.725 & 9,4 \\
\hline Estrangeiro & 1 & 2 & 3 & 0,0 \\
\hline Não especificado & 563 & 217 & 780 & 4,2 \\
\hline Total & 16.487 & 1.821 & 18.308 & 100,0 \\
\hline
\end{tabular}

Fonte: Livro de registro de passaporte do Governo Civil do Porto. Acervo do Arquivo Distrital do Porto.

Em seguida, aparecem os concelhos de Paços de Ferreira (na casa dos 700 imigrantes) e Paredes (na casa dos 400 imigrantes). Quanto mais distante do concelho do Porto, menor o número de deslocamentos, com exceção de Baião, já próximo à fronteira dos distritos de Vila Real e Viseu. Com um pouco mais de 300 saídas, encontram-se os concelhos de Maia, Baião, Santo Tirso e Vila do Conde. A esses, seguem-se Póvoa de Varzim, Amarante e Penafiel, que ficaram na faixa das 200 saídas. Por fim, Valongo, Marco de Canaveses, Felgueiras e Lousada foram os que apresentaram o menor número de imigrantes que se destinaram ao Pará, ficando um pouco acima de 100 saídas ao longo dos quase cem anos de levantamento.

Não é possível discutir nesse espaço as especificidades dos diversos concelhos, contudo, de maneira geral, é importante destacar que o concelho do Porto, embora fosse uma localidade com alto nível de urbanização, desenvolvimento industrial e meios de transporte internos, contrastava com outros concelhos de seu distrito, mais rurais, como, por exemplo, o de Gondomar, que, "a despeito da proximidade tangencial com a segunda cidade do país, era dominado pela agricultura apesar de a pequena indústria, sobretudo de madeiras e ourivesaria" (CRUZ, 2007, p. 462). 
FIGURA 1

Fluxo de imigrantes do distrito do Porto para o estado do Pará 1834-1930

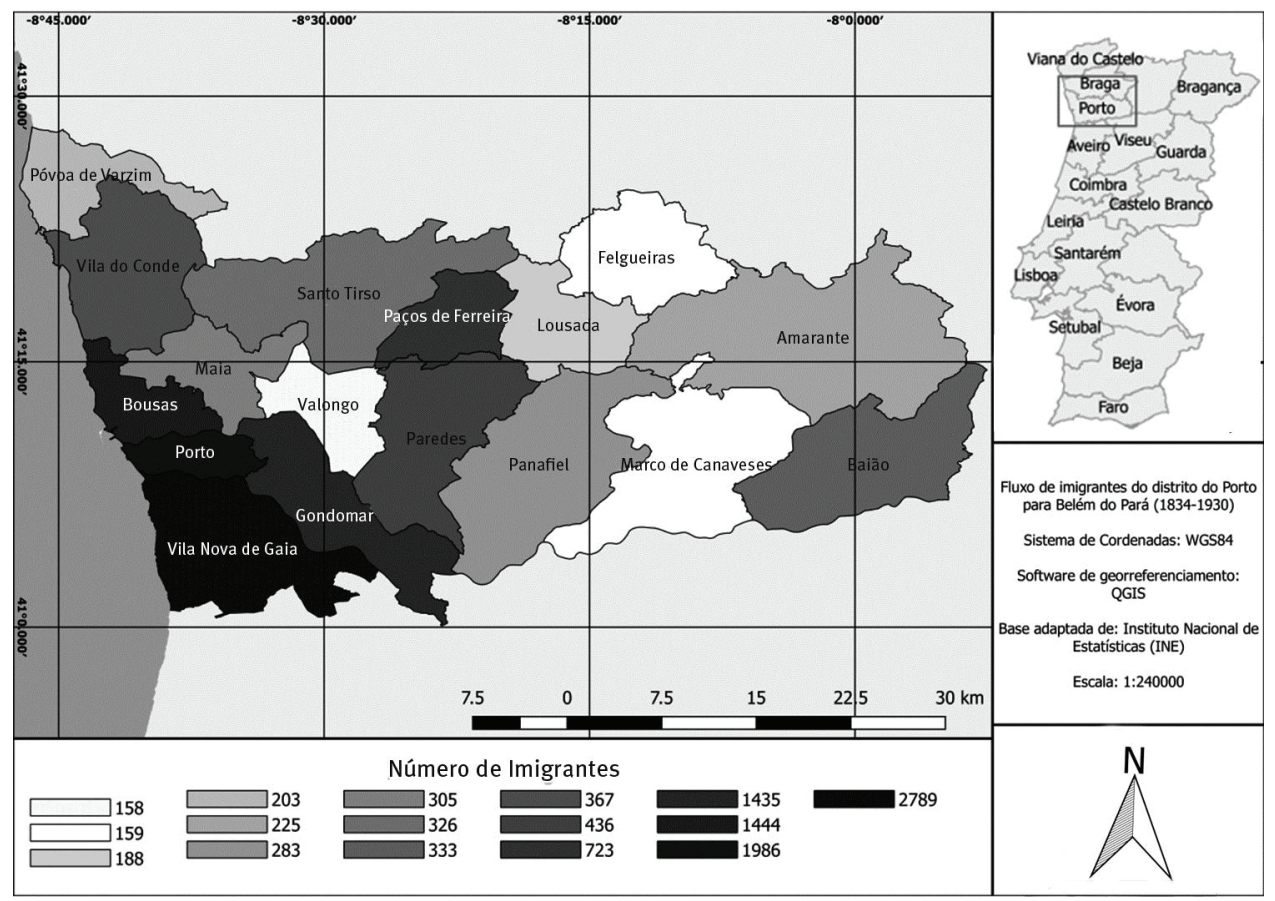

Fonte: Livro de registro de passaporte do Governo Civil do Porto. Acervo do Arquivo Distrital do Porto

\section{Considerações finais}

A análise quantitativa descritiva das fontes é um trabalho volumoso, mas que aproxima o pesquisador de um universo maior de pessoas. Fontes que permitem um tratamento serial, como os passaportes, podem limitar a análise das práticas cotidianas dos sujeitos, seus valores e representações, mas permitem dimensionar o volume dos deslocamentos, conhecer fragmentos das trajetórias individuais e familiares, sendo importantes para mensurar a presença portuguesa no Pará, que não se limita aos números e ao perfil da imigração, mas pode ter neles uma importante referência.

A partir da análise dos passaportes, ressaltou-se o impacto da Revolução Cabana nos deslocamentos para o Pará, que apresentaram números baixos, mas contínuos durante o conflito. Destacou-se, também, a influência das epidemias de cólera e de peste bubônica no distrito do Porto para o aumento da migração, evidenciando que, para além das causas estruturais relacionadas aos limites econômico-sociais portugueses e paraenses, fatores conjunturais foram fundamentais para entender o fluxo e suas variações.

Mesmo trabalhando com um volume significativo de anos e passaportes, os números encerram limites importantes que precisam ser matizados, não apenas por não darem conta 
da migração clandestina, mas também por subsumirem uma quantidade expressiva de pessoas que migravam na condição de acompanhante, sem passaporte individual, sendo apenas um nome no registro de outrem, silentes no cômputo geral. 0 mesmo acontece com os inúmeros indivíduos que cruzaram o Atlântico em diversos momentos, por mais de uma vez, solicitando um passaporte a cada viagem, reemigrando.

Neste trabalho foi demonstrada a relação estreita entre a crise do comércio da borracha e a queda do fluxo imigratório portuense em direção ao Pará, destacando a importância da economia local para a transformação do estado em um importante polo de atração de população, particularmente na virada do século XIX para o XX, quando ficou atrás apenas do Rio de Janeiro, ocupando o segundo lugar na escolha dos imigrantes, passando para o terceiro nas décadas iniciais do século XX, quando foi ultrapassado por São Paulo. Trata-se de um fluxo marcadamente masculino, em que as mulheres sempre estiveram presentes, particularmente a partir do final dos oitocentos, em uma escala crescente, diminuindo a distância numérica em relação aos imigrantes masculinos.

Para além dos dados quantitativos, o volume expressivo de registros conforma um corpo documental importante para seguir os nomes e os caminhos desses homens e mulheres que saíram de seus concelhos em direção ao Porto, elegendo o Pará como destino. Por vezes, eles vinham sem referência acerca do estado ou tinham ruídos de informação amealhada nas notícias dos jornais, das cartas, dos comentários de um familiar ou conterrâneo que já havia realizado a travessia. Dessa maneira, as histórias individuais podem tomar forma e as trajetórias de uma pessoa, de uma família ou de sujeitos de um mesmo concelho podem ser seguidas por meio dos passaportes, mas isso fica para uma próxima viagem!

\section{Referências}

ALMEIDA, M. A. P. As epidemias nas notícias em Portugal: cólera, peste, tifo, gripe e varíola 18541918. História, Ciências e Saúde Manguinhos, Rio de Janeiro, v. 21, n. 2, p. 687-708, abr.-jun. 2014.

ALVES, J. F. Lógicas migratórias no Porto oitocentista. Emigração/imigração em Portugal. In: NIZZA da SILVA, M. B. et al. (org.). Actas do colóquio internacional sobre emigração/imigração em Portugal (sec XIX-XX). Porto: Fragmentos, 1993. p. 87-97.

ALVES, J. F. Os brasileiros: emigração e retorno no Porto oitocentista. Porto: Gráficas Reunidas, 1994.

ALVES, J. F. Emigração e sanitarismo - Porto e Brasil no século XIX. Ler História, n. 48, p. 141156, 2005.

ARROTEIA, J. C. A emigração portuguesa: suas origens e distribuição. Lisboa: Instituto de Cultura e Língua Portuguesa/ Ministério da Educação, 1983.

BASSANEZZI, M. S. Mulheres que vêm, mulheres que vão. In: PINSKY, C.; PEDRO, J. Nova história das mulheres. São Paulo: Editora Contexto, 2012. p. 169-193.

BELTRÃO, J. F. Cólera: o flagelo da Belém do Grão-Pará. Belém: Editora da UFPA/Goeldi Editoração, 2004.

BRETTELL, C. Homens que partem, mulheres que esperam. Lisboa: Dom Quixote, 1991. 
CANCELA, C. D.; COSME, J. R. Entre fluxos, fontes e trajetórias: imigração portuguesa para uma capital da Amazônia (1850-1920). Revista Estudos Ibero-Americanos, Porto Alegre, v. 42, n. 1, p. 232-254, jan.-abr. 2016

CARVALHO, M. A. Bebendo açaí comendo bacalhau: perfil e práticas da sociabilidade lusa em Belém do Pará entre finais do século XIX e início do XX. 2011. Tese (Doutorado em História) Universidade do Porto, Porto, 2011.

CHAMBOULEIRON, R. Povoamento, ocupação e agricultura na Amazônia colonial (1640-1706). Belém: Editora Açaí, 2010.

COSME, J. S. R. Quadros da emigração portuguesa para o Pará (Brasil): 1886-1900. Naveg@mérica. Revista electrónica editada por la Asociación Española de Americanistas, n. 15, 2015.

CRUZ, M. A. Eleições no Porto e em Gondomar: da monarquia para a república. Revista da Faculdade de Letras-História, Porto, III série, v. 8, p. 459-479, 2007.

EMMI, M. F. Um século de imigrações internacionais na Amazônia brasileira (1850-1950). Belém: NAEA, 2013.

FERRARIA, M. J.; AMORIM, P. A emigração para o Brasil através dos livros de registo de passaporte do Governo Civil do Porto (1880-1890). In: SOUSA, F.; MARTINS, I. A emigração portuguesa para o Brasil. Porto: Cepese; Rio de Janeiro: Faperj, 2007. p. 209-220.

FERREIRA, D. A emigração do norte de Portugal para o Brasil: uma primeira abordagem (19181931). In: SARGES, M. et al. (org.). Entre mares: o Brasil dos portugueses. Belém: Pakatatu, 2010. p. 145-159.

FERREIRA, M. Os portugueses do Brasil, atores das relações luso-brasileiras, fim do século XIX início do século XX. Rio de Janeiro: Arquivo da Cidade do Rio de Janeiro, 2007. Disponível em: 〈www0.rio.rj.gov.br/arquivo/pdf/quartas_no_arquivo/2007/palestra_MarieJoFerreira.pdf〉. Acesso em: 8 jun. 2013.

FONTES, E. Preferem-se portugues(as): trabalho, cultura e movimento social em Belém do Pará (1885-1914). 2002. Tese (Doutorado em História) - Universidade Estadual de Campinas (Unicamp), Campinas, 2002.

GUIMARÃES, L. A. V. De chegadas e partidas: migrações portuguesas no Pará (1800-1850) migrações e trajetórias de vidas de portugueses no Pará (1800-1850). Jundiaí: Paco Editorial, 2018.

HOMEM, A. C. Jacobinos, liberais e democratas na edificação de Portugal contemporâneo. In: TENGARRINHA, J. História de Portugal. São Paulo: Unesp; Bauru, SP: Edusc, 2000. p. 263-282.

KLEIN, H. A integração social e económica dos imigrantes portugueses no Brasil nos finais do século XIX e no século XX. Análise Social, v. 28, n. 121, p. 235-265, 1993.

LEITE, J. C. Emigração portuguesa: a lei e os números. Análise Social, v. XXIII, n. 3, p. 463-480, 1987.

LEITE, J. C. O transporte de emigrantes: da vela ao vapor na rota para o Brasil, 1851-1914. Análise Social, v. XXVI, p. 741-752, 1991.

LEITE, J. C. O Brasil e a emigração portuguesa. In: FAUSTO, B. (org.). Fazer a América. São Paulo: Edusp, 2000. p. 185.

MAIA, F. P. S.; MONTEIRO, I. B. Impactos da emigração portuguesa para o Brasil no norte de Portugal - finais do séc. XIX e inícios do XX. Navegar, v. 1, n. 1, p. 122-149, jul.-dez. 2015.

MASSEY, D. Patterns and processes of international migration in the 21st century. In: CONFERENCE ON AFRICAN MIGRATION IN COMPARATIVE PERSPECTIVE. Proceedings [...]. Johannesburg, South Africa, 4-7 June 2003. 
MATOS, M. I. Âncora de emoções: a imigração portuguesa. Cadernos CERU, série 2, v. 19, n. 1, junho 2008.

MATOS, M. Portugueses: deslocamentos, experiências e cotidiano. São Paulo, séculos XIX e XX. Bauru: Edusc, 2013.

MATOS, M. I. S.; TRUZZI, O.; CONCEIÇÃO, C. F. Mulheres imigrantes: presença e ocultamento (interiores de São Paulo, 1880-1930). Revista Brasileira de Estudos de População, v. 35, n. 3, 2018.

MENDES, J. S. R. Laços de sangue: privilégio e intolerância à imigração portuguesa no Brasil. Porto: Cepese, 2010.

MENEZES, L. M.; MATOS, M. I. S. Gênero e imigração: mulheres portuguesas em foco (Rio de Janeiro e São Paulo - XIX e XX). São Paulo: e-Manuscrito, 2017.

PEIXOTO, J. As teorias explicativas das migrações: teorias micro e macro-sociológicas. Lisboa: Instituto Superior de Economia e Gestão (SOCIUS), 2004. (Working Paper, 11/2004)

PONTES, D. 0 cerco da peste no Porto: cidade, imprensa e saúde pública na crise sanitária de 1899. Dissertação (Mestrado) - Universidade do Porto, Porto, Portugal, 2012.

RIBEIRO, G. S. O imigrante e a imigração portuguesa no acervo da Justiça Federal do Rio de Janeiro. Revista População e Sociedade, n. 14-15, parte I, p. 121-142, 2007.

RICCI, M. Cabanagem, cidadania e identidade revolucionária ao problema do patriotismo na Amazônia entre 1835-1840. Tempo, v. 11, n. 22, p. 5-30, 2007.

ROCHA, I. P. Imigração internacional em São Paulo - retorno e reemigração (1890-1920). Dissertação (Mestrado) - Universidade de São Paulo (USP), São Paulo, 2007.

ROCHA, R. A emigração do Porto para o Brasil durante a primeira guerra mundial (1914-1918). In: SOUSA, F. et al. Um passaporte para a terra prometida. Porto: Fronteira do Caos/Cepese, 2011.

RODRIGUES, T. A população portuguesa nos séculos XIX e XX: o acentuar das assimetrias de crescimento regional. População e Sociedade, n. 1, p. 57-86, 1995.

SANTOS, P. M. dos; FERREIRA, D. As relações Portugal-Brasil e a emigração portuguesa. 0 impacto da legislação nacionalista de Getúlio Vargas. História. Revista da FLUP, IV série, v. 7, p. 35-56, 2017.

SERRÃO, J. A emigração portuguesa: sondagem histórica. 4. ed. Lisboa: Livros Horizonte, 1982.

SARMENTO, C. A. A. M. Emigração familiar para o Brasil do distrito de Braga, no ano de 1912. In: SOUSA, F. de; MARTINS, I. de L.; MATOS, I. (coord.). Nas duas margens: os portugueses no Brasil. Porto: Edições Afrontamento; Cepese, 2009. p. 290-291.

SCOTT, A. S. V. Uma história de despedidas: a migração portuguesa para o Brasil (1822-1914). Revista de Ciências Humanas, Florianópolis, n. 27, p. 29-56, abr. 2000.

SILVA, H. D. Reformas administrativas em Portugal desde o século XIX. Jurismat: Revista Jurídica, Portimão, n. 1, p. 65-97, 2012.

SOUSA, F. et al. A emigração portuguesa para o Brasil e as origens da Agência Abreu (1840). Lisboa: Fronteira do Caos Editores, 2009 (Coleção os Portugueses no Mundo).

\section{Sobre a autora}

Cristina Donza Cancela é doutora em História pela Universidade de São Paulo (USP) e mestre em Antropologia Social pela Universidade Estadual de Campinas (Unicamp). Professora do Programa de Pós-Graduação em História Social da Amazônia e do Programa de PósGraduação em Antropologia da Faculdade de História da Universidade Federal do Pará (UFPA). Investigadora integrada da Universidade de Lisboa e pesquisadora PQ-2 do CNPq. 


\title{
Endereço para correspondência
}

Travessa Nove de Janeiro, n. 2076, apt. 802, Bairro São Brás

66065-585 - Belém-PA, Brasil

\begin{abstract}
Immigration flux from the district of Porto to the state of Pará: rubber, conflicts, epidemics and gender (1834-1930)

The article analyzes immigration from the Porto district to Pará, between 1834 and 1930, through passport records from the Civil Government of Porto. It observes the flow through the decades, emphasizing the economic and social issues associated to these displacements as well as specific aspects such as epidemics and social conflicts, highlighting the "Revolta da Cabanagem" (Cabanagem Rebellion) on a local scale and the First World War on a global scale. It analyzes the influence of passport holders' companions and re-migration on migrants' flows, followed by research into the profile of the immigrants regarding origin and the naturality by district and Portuguese "concelhos". Finally, the article problematizes female migration and the gender issues it involves, pointing to the asymmetry of women's displacement, always smaller in relation to men, but showing growth in the first decades of the twentieth century.
\end{abstract}

Keywords: Portuguese immigration. Pará. Flow. Profile. Passport. Gender.

\section{Resumen}

El flujo migratorio del distrito de Oporto hacia el estado de Pará: caucho, conflictos, epidemias y género (1834-1930)

El artículo analiza la inmigración del distrito de Oporto hacia Pará, entre los años 1834 y 1930, a través de los registros de pasaporte del Gobierno Civil de Oporto. Observa el flujo a través de las décadas y resalta las cuestiones económicas y sociales que impulsaran esos desplazamientos, así como aspectos puntuales como epidemias y conflictos sociales, con énfasis en la Revolta da Cabanagem (Revuelta de Cabanagem) a escala local y en la Primera Guerra Mundial a escala global. Analiza la influencia de los acompañantes de los titulares de pasaportes y de la reemigración en el flujo de migrantes. Sigue investigando el perfil de los inmigrantes en cuanto al origen y naturalidad por distrito y concelho portugués. Por último, problematiza la migración femenina y las cuestiones de género que la envuelven, apuntando a la asimetría de los desplazamientos de mujeres, siempre en menor cantidad en relación con los de los hombres, pero con crecimiento en las primeras décadas del siglo XX.

Palabras clave: Inmigración portuguesa. Pará. Flujo. Perfil. Pasaporte. Género.

Recebido para publicação em 08/04/2019 Aceito para publicação em 30/08/2019 